\title{
IMPROVEMENT OF FOREST FIRE DETECTION ALGORITHM USING BRIGHTNESS TEMPERATURE LAPSE RATE CORRECTION IN HIMAWARI-8 IR CHANNELS: APPLICATION TO THE 6 MAY 2017 SAMCHEOK CITY, KOREA
}

\author{
S. H. Park ${ }^{1}$, W. Park ${ }^{2}$, H. S. Jung ${ }^{1, *}$ \\ ${ }^{1}$ Dept. of Geoinformatics, University of Seoul, Korea - (psh5759, hsjung)@uos.ac.kr \\ ${ }^{2}$ Dept. of Earth System Sciences, Yonsei University - pwpw1983@ gmail.com
}

ICWG III/IVa

KEY WORDS: Forest Fire, Himawari-8, Brightness Temperature Lapse Rate, Height Correction

\begin{abstract}
:
Forest fires are a major natural disaster that destroys a forest area and a natural environment. In order to minimize the damage caused by the forest fire, it is necessary to know the location and the time of day and continuous monitoring is required until fire is fully put out. We have tried to improve the forest fire detection algorithm by using a method to reduce the variability of surrounding pixels. We focused that forest areas of East Asia, part of the Himawari-8 AHI coverage, are mostly located in mountainous areas. The proposed method was applied to the forest fire detection in Samcheok city, Korea on May 6 to 10, 2017.
\end{abstract}

\section{INTRODUCTION}

Forest fires are a major natural disaster that destroys a forest area and a natural environment. In order to minimize the damage caused by the forest fire, it is necessary to know the location and the time of day and continuous monitoring is required until fire is fully put out. In this respect, it is very useful to use Himawari-8 AHI images which can cover global area at intervals of 10 minutes. Since the Himawari-8 AHI provides channel images similar to the GOES-R and MODIS Aqua/Terra, it is easy to apply the forest fire detection algorithms used in these satellites(Giglio et al. 2003; Giglio et al. 2016; Justice et al. 2002).

The key point of the developed forest fire detection algorithms is that the brightness temperatures of a forest fire pixel in midwave infrared (MWIR) and thermal infrared (TIR) channel are larger than its surrounding pixels(Csiszar et al. 2006; Kaufman et al. 1998). When the brightness temperature of a particular pixel is located outside the confidence interval $99 \%$ of the probability distribution, it is classified as a fire pixel. A massive forest fire or an active forest fire is easily detected because it shows a very high brightness temperature than surrounding areas, but a small fire or a fire in early stage is difficult to classify as an outlier because its brightness temperature is similar to the surrounding area(Giglio et al. 2016; Justice et al. 2002).

Thus, there are two ways to improve the performance of the forest fire detection algorithm without adjusting the confidence interval. The first direction is to increase the brightness temperature difference between the forest fire pixel and the surrounding pixels. The second direction is to statistically classify as an outlier by reducing the variability of the brightness temperature values of the surrounding pixels.

The objective of this study is to improve the forest fire detection algorithm by using a method to reduce the variability of surrounding pixels. We focused that forest areas of East Asia, part of the Himawari-8 AHI coverage, are mostly located in mountainous areas.

\section{METHODS}

The description of the proposed method is as follows. First, the brightness temperature images were generated from the Himawari-8 AHI image of the MWIR channel. Second, total of 771 points are selected as reference points in order to estimate the temperature lapse rate in the Himawari-8 AHI image. The selected reference points are located in the middle of highly varied mountainous areas, such as the Himalayas, around the Mt. Baekdu in the Korean peninsula, Mt. Fuji in Japan, Taiwan island, northern Philippines, Malaysia, Indonesia and eastern Australia, etc. Second, total of 77,100 sets are constructed by selecting 100 random target points that are 10-20 pixel distance from each reference point. Third, linear regression analysis is performed using the difference of altitude from the selected sets as independent variable and the difference of brightness temperature as the dependent variable at the imaging time. The analysis was performed except when randomly selected target points were located in the cloud or water area. The slope coefficient derived from the linear regression analysis is assumed to be the temperature lapse rate at the imaging time. Finally, the estimated brightness temperature lapse rate is used to compensate for the variation of brightness temperature due to altitude in the MWIR and TIR channel images.

\section{STUDY AREA AND DATA}

The proposed method was applied to the forest fire detection in Samcheok city, Korea on May 6 to 10, 2017. Samcheok city is located in Gangwon province where the altitude change is severe on the Korean peninsula. It is suitable for evaluating the height correction results. The effect of proposed correction method was analysed by using 20 images of Himawari-8 AHI MWIR and TIR channels every 6 hours.

\footnotetext{
* Corresponding author
} 


\section{RESULTS AND ANALYSIS}

Figure 1 shows the surface temperature lapse rate estimated at 18:00 on May 6, 2017 (UTC). As can be seen in the figure 1, when the height difference between the reference and the target point increases, the difference in the surface temperature also increases. It is possible to estimate the rate of surface temperature decrease by linear regression analysis, and the estimated surface temperature lapse rate can be used to compensate the surface temperature affected by altitude.

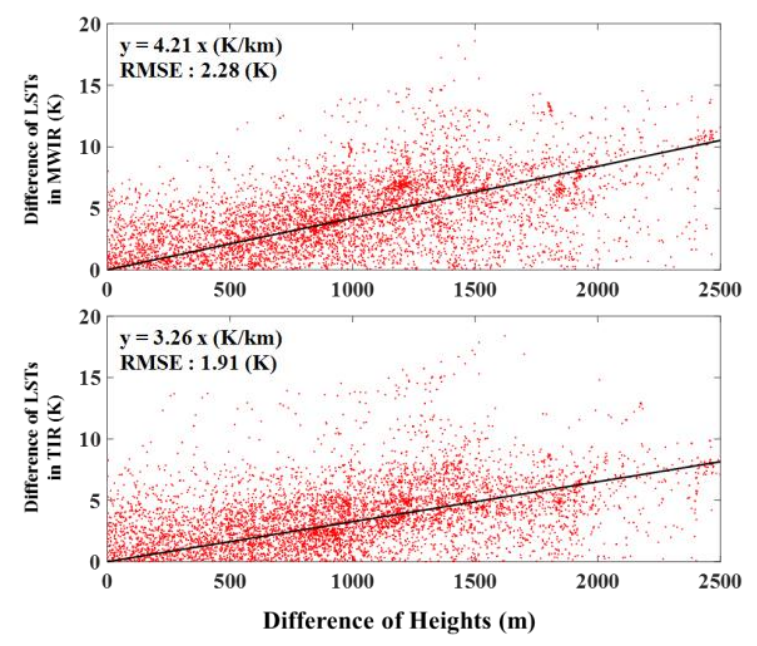

Figure 1. Estimated brightness temperature lapse rate at 18:00 on May 6, 2017 (UTC)

Figure 2 shows the MWIR images with the height effect corrected using the surface temperature lapse rate. The region with the greatest change is the high-altitude areas such as the Kangwon province and the Mt. Baekdu area.

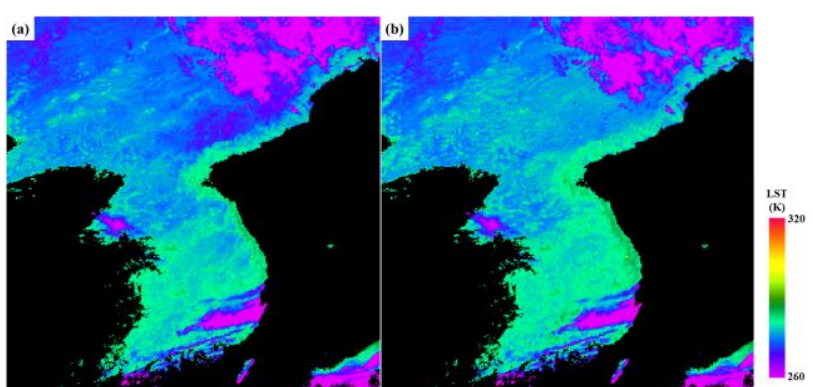

Figure 2. Before and after correction of height effect in MWIR image

Figure 3 shows the Samcheok City where the forest fire occurred. Through the height correction, we can see that the surface temperatures of the pixels around the forest fire pixels have similar values. As a result of analyzing through 20 images, the standard deviation around the forest fire before the height correction was $3.52 \mathrm{~K}$. The standard deviation around the forest fire after the height correction decreased to $2.72 \mathrm{~K}$. The standard deviation value was reduced by about $23 \%$ through height correction.

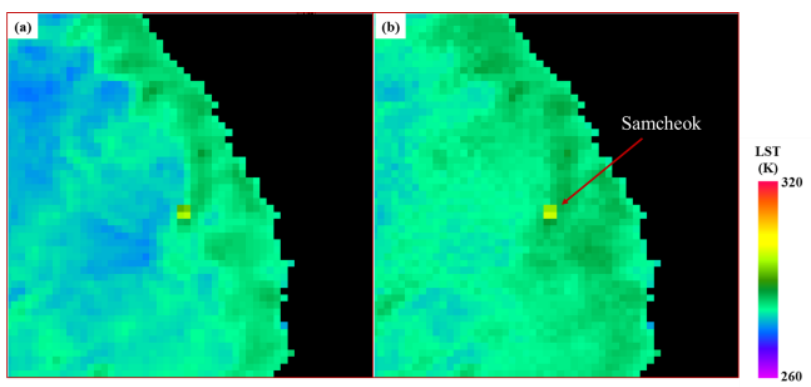

Figure 3. Before and after correction of height effect in Samcheok City

\section{CONCLUSION}

In this study, the standard deviations around the forest fire pixel before and after the height correction was compared to improve the forest fire detection algorithm. A method for estimating the surface temperature lapse rate for height correction is proposed and suggested that the effect of height can be compensated by the estimated surface temperature lapse rate. The reduction of the standard deviation value around the forest fire pixel indicate that forest fire pixel is considered to be more easily classified as an outliers.

\section{ACKNOWLEDGEMENTS}

This study was funded by the Korea Meteorological Administration Research and Development Program [Grant number KMI2017-9060].

\section{REFERENCES}

Csiszar, I.A., Moriette, J.T., and Giglio, L., 2006. Validation of active fire detection from moderate-resolution satellite sensors: the MODIS example in Northern Eurasia. IEEE Transactions on Geoscience and Remote Sensing, 44. pp. 1757-1764.

Giglio, L., Descloitres, J., Justice, C.O., and Kaufman, Y.J., 2003. An enhanced contextual fire detection algorithm for MODIS. Remote Sensing of Environment, 87, pp. 273-282.

Giglio, L., Schroeder, W., and Justice, C.O., 2016. The collection 6 MODIS active fire detection algorithm and fire products. Remote Sensing of Environment, 178, pp. 31-41.

Justice, C.O., Giglio, L., Korontzi, S., Owens, J., Morisette, J.T., Roy, D., Descloitres, J., Alleaume, S., Petitcolin F., and Kaufman, Y., 2002. The MODIS fire products, Remote Sensing of Environment, 83, pp. 244-262.

Kaufman, Y.J., and Remer, L.A., 1994. Detection of forests using Mid-IR reflectance: An application for aerosol studies. IEEE Transactions on Geoscience and Remote Sensing, 32(3), pp. 672-683. 